LA-UR-02-3852

Approved for public release; distribution is unlimited.

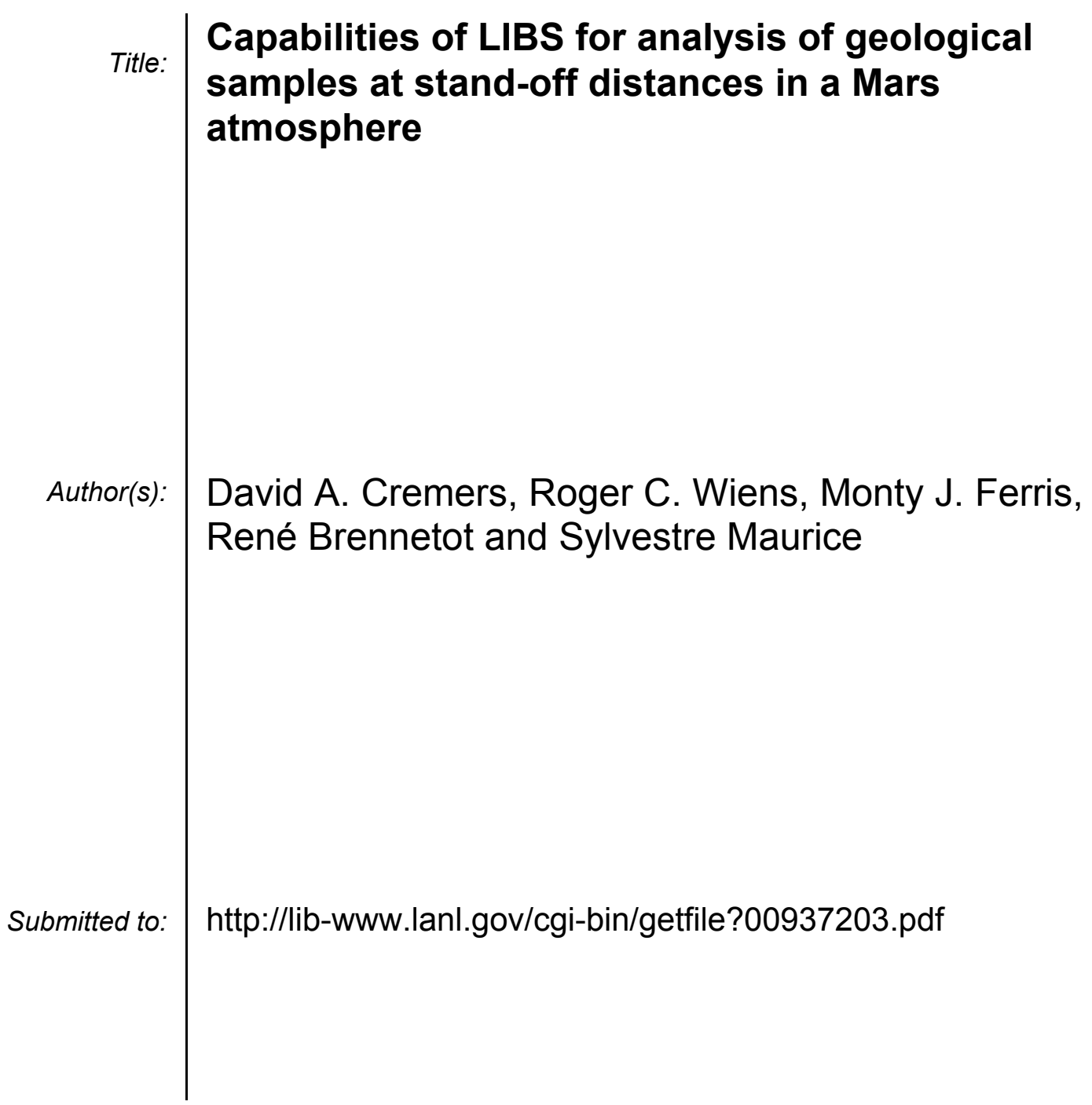




\title{
Capabilities of LIBS for analysis of geological samples at stand-off distances in a Mars atmosphere
}

\author{
David A. Cremers ${ }^{1}$, Roger C. Wiens ${ }^{2}$, and Monty J. Ferris ${ }^{1}$ \\ ${ }^{1}$ Advanced Diagnostics and Instrumentation, MS J565 \\ ${ }^{2}$ Atmospheric and Space Sciences, MS D466 \\ Los Alamos National Laboratory, Los Alamos, NM 87545 \\ Tel: 505-665-4180; Fax: 505-665-6095:e-mail: cremers_david@lanl.gov \\ René Brennetot \\ CEA Saclay, Fuel Cycle Division, LALES DEN/DPC/SCPA Bâtiment 391, 91191 Gif sur Yvette France \\ Tel : (33) 1690877 53; Fax: (33) 1690877 38; e-mail : $\underline{\text { brennetot@carnac.cea.fr }}$ \\ Sylvestre Maurice \\ Midi Pyrenees Observatory \\ Tel : (33) 5613329 4;7 Fax : (33) 1613328 40; e-mail : maurice@ast.obs-mip.fr
}

\begin{abstract}
The use of LIBS for stand-off elemental analysis of geological and other samples in a simulated Mars atmosphere is being evaluated. Analytical capabilities, matrix effects, and other factors effecting analysis are being determined.

$\checkmark 2000$ Optical Society of America

OCIS codes: (140.3440) Laser-Induced Breakdown; (300.6210) Atomic Spectroscopy; (300.2140) Emission
\end{abstract}




\title{
Capabilities of LIBS for analysis of geological samples at stand-off distances in a Mars atmosphere
}

\author{
David A. Cremers ${ }^{1}$, Roger C. Wiens ${ }^{2}$, and Monty J. Ferris ${ }^{1}$ \\ ${ }^{1}$ Advanced Diagnostics and Instrumentation, MS J565 \\ ${ }^{2}$ Atmospheric and Space Sciences, MS D466 \\ Los Alamos National Laboratory, Los Alamos, NM 87545 \\ Tel: 505-665-4180; Fax: 505-665-6095:e-mail: cremers_david@lanl.gov \\ René Brennetot \\ CEA Saclay, Fuel Cycle Division, LALES DEN/DPC/SCPA Bâtiment 391, 91191 Gif sur Yvette France \\ Tel : (33) 1690877 53; Fax : (33) 1690877 38; e-mail : brennetot@carnac.cea.fr \\ Sylvestre Maurice \\ Midi Pyrenees Observatory \\ Tel : (33) 56133294 ;7 Fax : (33) 1613328 40; e-mail : maurice@ast.obs-mip.fr
}

\section{Introduction}

Through funding from NASA's Mars Instrument Development Program (MIDP), we have been evaluating the use of LIBS for future use on landers and rovers to Mars. Of particular interest is the use of LIBS for stand-off measurements of geological samples up to 20 meters from the instrument. Very preliminary work on such remote LIBS measurements based on large laboratory type equipment was carried out about a decade ago [1]. Recent work has characterized the capabilities using more compact instrumentation [2] and some measurements have been conducted with LIBS on a NASA rover testbed [3].

There is interest in LIBS for this application because of its many unique analysis capabilities compared to methods of elemental analysis used on previous missions and instruments being considered for near term flights. These are methods are x-ray fluorescence (Viking) and APXS (Pathfinder and two 2003 missions). Important LIBS advantages include: (1) Rapid analysis - i.e. each laser pulse generates one plasma and one measurement. (Many spectra may be averaged together, however, to increase accuracy/precision and average out sample inhomogeneities.); (2) All elements (high and low z) can be detected; (3) Stand-off analysis capability - the laser pulse can be focused at a distance on a solid to generate the laser plasma for remote analysis [4]; (4) Surface cleaning - repetitive sampling at the same spot permits ablation through weathered surfaces to reach the underlying bulk rock and provides ejection of dust from a surface [2].

\section{Experimental apparatus}

Two set-ups were used here. The first consisted of a large laboratory-sized laser (Spectra-Physics GCR-11) and spectrograph (Chromex $0.5 \mathrm{~m}$ ) with a gated CCD detector (Andor Technology, InstaSpec V). This system was similar to that used in a previous study [2]. The second set-up was a prototype LIBS instrument used on 2000/2001 rover [3] and field tests. It consists of a compact flashlamp-pumped Nd:YAG laser ( $80 \mathrm{~mJ} / \mathrm{pulse}, 0.1 \mathrm{~Hz}, 1064 \mathrm{~nm})$, an adjustable beam focusing system $(6.4 \mathrm{~cm}$ diameter lens) to focus the pulses on remotely located samples and collect the plasma light. The collected light is transported to the detection system consisting of a compact echelle spectrograph (Catalina Scientific Inc., $\square / \square \square=2500$ ) and a gated-intensified array detector. Data analysis is provided by manufacturer-supplied software and software written in-house combining peak searches with calibration protocols.

\section{Analysis requirements for Mars}

This work is being carried out with emphasis on analysis requirements important to understanding Mars geology. Current knowledge is based on data from XRF (Viking) and APXS (Pathfinder), from the SNC meteorites, and from remote sensing, (TES, Themis, and GRS data). Only major element compositions have been obtained directly using XRF and APXS as TES and Themis can only infer elemental compositions. Minor and trace elements have been determined from the SNC meterorites, however. Uncertainties in major element concentrations have been large (Fe $\sim 25 \%$ and $\mathrm{Si} \sim 10 \%$ [5]), which, along with the absence of mineralogical data, has left ambiguous whether the rocks were igneous or sedimentary [6]. In addition, the existence of weathered coatings on the rocks complicates the issue as the true composition of the underlying rock may not have been measured: TES results suggest that much of the 
northern hemisphere is andesitic [7] but the data may also be interpreted as partially weathered basalt [8]. Detailed characterization of such coatings, if they exist, is very important not just to understand the underlying rock types, but also because of the wealth of information regarding atmosphere-surface interactions leading to weathering. Therefore, it is important that major elements be measured to $\pm 10 \%$ and to have the ability to ablate through with the capability to remove dust coatings and to depth profile through weathering rinds or coatings, at a spatial resolution of several microns.

Minor and trace element compositions are important in determining the provenance of rocks and dusts. For example, the global dust component likely arose from a combination of basaltic weathering plus a sulfur-rich component of either volcanic aerosol or hydrothermal origin. Major elements cannot distinguish between these components, but minor and trace element compositions should be completely diagnostic, as ratios such as $\mathrm{Ba} / \mathrm{Li}$ or $\mathrm{Zn} / \mathrm{Li}$ are predicted to vary by several orders of magnitude between proposed sources [9]. Likewise, minor and trace elements are important constraints on sedimentary processes. Therefore trace element detection of at least 10 species should be measurable with detection limits $<100 \mathrm{ppm}$ to $\pm 40 \%$, including $\mathrm{Ba}, \mathrm{Li}, \mathrm{Rb}$, Sr with detection limits $\square 20$ $\mathrm{ppm}$. The ability to measure these separately in dust and in pristine rocks is required.

\section{Matrix effects}

The laser spark is known to exhibit both physical and chemical matrix effects. These can limit the ability to quantify a LIBS measurement, especially for complex matrices represented by geological samples. An example of the effect

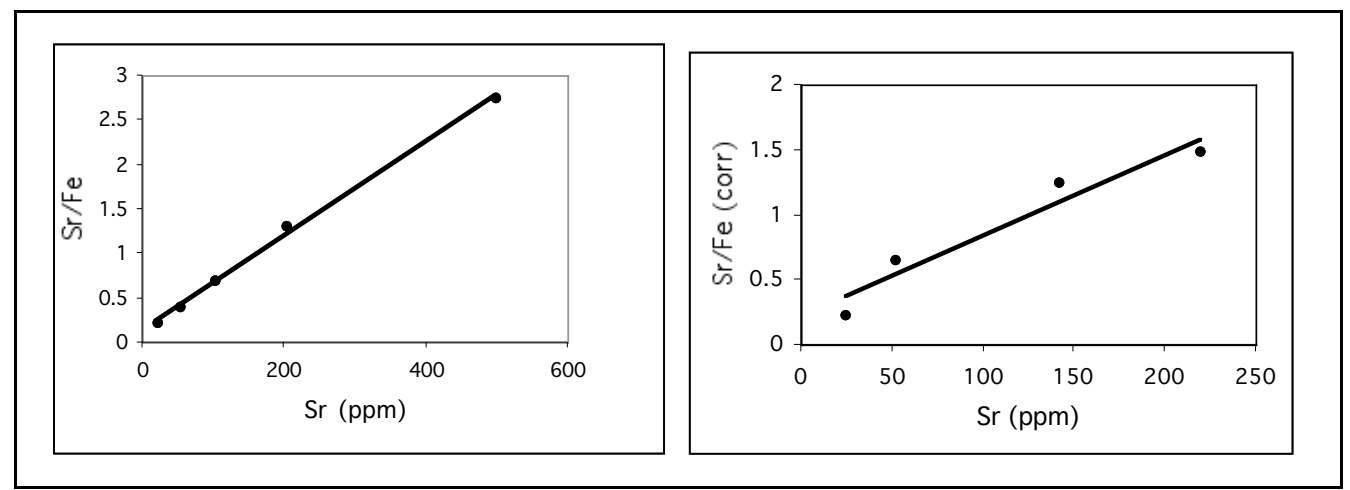

Fig. 1. Calibration curves for the detection of $\mathrm{Sr}$ in (left) synthetic silicates samples having the same bulk composition and (right) stream sediments with different bulk matrix compositions.

of the matrix is shown in Figure 1. The data on the left refers to a calibration curve prepared using a set of synthetic silicate standards with a uniform bulk matrix composition but having significant variations in trace and minor elements. The data on the right correspond to stream sediment samples with variations in the concentration of major elements composing the matrix. These data were obtained with the samples placed in a 7 Torr $\mathrm{CO}_{2}$ atmosphere at a distance of $19 \mathrm{~m}$. Pulses of $80 \mathrm{~mJ}$ were used to interrogate the samples. It is clear that the bulk matrix effects the calibration for $\mathrm{Sr}$ as the data obtained using samples having different bulk compositions is significantly less correlated than the data obtained using samples having the same bulk compositions. Similar results showing greater difference between the two curves were obtained for other elements. The physical states of the samples used here were are identical,1 all being finely ground powders of uniform size. In terms of use on board a Mars lander or rover, the complete lack of sample preparation capability limits the ability to quantify even more. Therefore, study of the effect of the matrix both in terms of sample inhomogeneity and differences in bulk composition is important.

\section{Detection Limits, Accuracy, and Precision}

Measurement accuracy and precision are important for reasons described in Section 3. Representative values of

Table 1. Accuracy and Precision

\begin{tabular}{|l|l|l|} 
element & accuracy & precision \\
\hline $\mathrm{Al}$ & $4.4 \%$ & $5.1 \%$ \\
\hline $\mathrm{Cr}$ & 7.7 & 5.6 \\
\hline $\mathrm{Mg}$ & 3.2 & 5.2 \\
\hline $\mathrm{Mn}$ & 4.2 & 3.8 \\
\hline $\mathrm{Si}$ & 4.7 & 3.7 \\
\hline $\mathrm{Sr}$ & 6.3 & 6.5 \\
\hline
\end{tabular}


these are listed in Table 1 for measurements taken at a distance of 2.3 meters using the compact LIBS prototype instrument and 14 certified standards as samples.

\section{Other Detection Capabilities}

In addition to geological targets, other targets are of interest such as ice (i.e. for missions that may focus on the Mars polar regions). The ability to detect ice is shown in Figure 2. Identification is via the $\mathrm{OH}$ bandhead emission at $306.4 \mathrm{~nm}$. This spectrum was acquired at a distance of 3 meters with the ice sample in 7 Torr $\mathrm{CO}_{2}$. In addition to the simple identification of ice as evidence of water, there is also interest in detecting dusts that may be mixed with the ice and have become stratified over time.

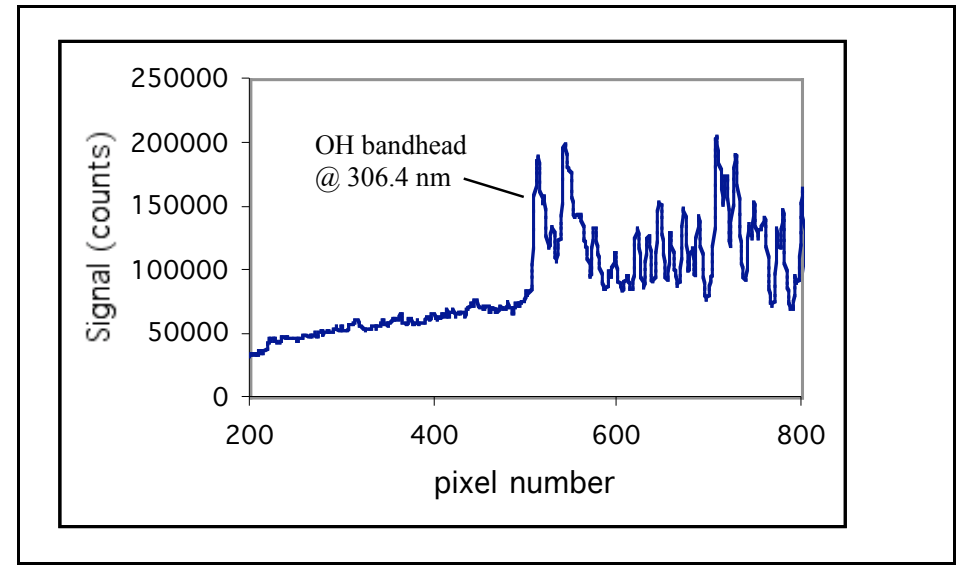

Fig. 2. LIBS spectrum acquired from an ice sample using the compact LIBS prototype instrument. The OH bandhead at $306.4 \mathrm{~nm}$ is clearly evident

\section{References}

[1] J.D. Blacic, D.R. Pettit, and D.A. Cremers, "Laser-Induced Breakdown Spectroscopy for Remote Elemental Analysis of Planetary Surfaces," in the Proceedings of the International Symposium on Spectral Sensing Research, Maui, HI, November 15-20 (1992).

[2] A.K. Knight, N.L. Scherbarth, D.A. Cremers, and M.J. Ferris, "Characterization of Laser-Induced Breakdown Spectroscopy (LIBS) for Application to Space Exploration," Appl. Spectrosc. 54, 331 (2000).

[3] R.C. Wiens, R.E. Arvidson, D.A. Cremers, M.J. Ferris, J.D. Blacic, and F.P. Seelos,IV, "Combined remote mineralogical and elemental measurements from rovers: Field and laboratory tests using reflectance and laser induced breakdown spectroscopy," J. Geophys. Res., Planets, accepted for publication (2002).

[4] D.A. Cremers, "Analysis of Metals at a Distance Using Laser-Induced Breakdown Spectroscopy," Appl. Spectrosc. 41, 572-57 (1987).

[5] J. Bruckner, G. Dreibus, R. Rieder, and H. Wanke H., "Revised data of the Mars Pathfinder Alpha Proton X-ray Spectrometer: Geochemical behavior of major and minor elements," Lunar Planet. Sci. XXXII, abstr \# 1293, The Lunar and Planetary Institute, Houston, TX (2001).

[6] H.Y. McSween Jr., S.L. Murchie, J.A. Crisp, N.T. Bridges, R.C. Anderson, J.F. Bell, D.T. Britt, J. Bruckner, G. Dreibus, Economou T., A. Ghosh, M.P. Golombek, J.P. Greenwood, J.R. Johnson, H.J. Moore, R.V. Morris, T.J. Parker, R. Rieder, R. Singer, H. Wanke, "Chemical, multispectral, and textural constraints on the composition and origin of rocks at the Mars Pathfinder landing site," J. Geophys. Res. 104, 8679-8715 (1999).

[7] J.L. Bandfield, V.E. Hamilton, and P.R. Christensen, "A Global View of Martian Surface Compositions from MGS-TES," Science 287, 1626-1630 (2000).

[8] H.Y. McSween, "Basalt or andesite? A critical evaluation of constraints on the composition of the ancient martian crust.” Lunar Planet Sci. XXXIII, 1062, The Lunar \& Planetary Institute, Houston, TX (2002).

[9] H.E. Newsom, J. J. Hagerty, and F. Goff, "Mixed hydrothermal fluids and the origin of the Martian soil," J.

Geophys. Res. (Planets), 104, 8717-8728, (1999). 